\title{
Home-school Travel: Analysis of Factors Affecting Italian Parents' Mode Choice
}

\author{
Natalia Distefano, Salvatore Leonardi*, Giulia Pulvirenti
}

Department of Civil Engineering and Architecture, University of Catania, Italy

Copyright $@ 2019$ by authors, all rights reserved. Authors agree that this article remains permanently open access under the terms of the Creative Commons Attribution License 4.0 International License

\begin{abstract}
Pedestrian injury is a major hazard to the health of children in most developed countries. Pedestrian accidents are one of the first causes of injury-related deaths and hospitalizations among children aged 5 to 14 in industrialized countries. This study has a dual objective: 1 ) to identify the factors affecting Italian parents' propensity to use private cars to accompany their children to school; 2) to analyze the availability of Italian parents to let their children walk to school alone. In order to develop this analysis, the data collected from a survey conducted in front of 9 schools (kindergartens and primary schools) in Catania were used. A path analysis was carried out to analyze these data. The results show that the habit of driving children to school is still very common in Italy. Main reasons why parents drive their children to school are the lack of safe home-school paths and the availability of regular or irregular parking spaces near the school. These results can be useful for those involved in transport planning and safety in order to implement effective actions aimed at encouraging the use of one or several human-powered modes of transportation such as walking or cycling. The results furthermore suggest that infrastructure-centered interventions, such as traffic calming measures and safer pedestrian crossings, can increase parents' safety perception of the home-school paths and thus raise the probability that children walk to school.
\end{abstract}

Keywords Child Safety, Home-school Paths, Road Accidents, Transport Mode, Path Analysis, Pyramid Diagram

\section{Introduction}

Children are vulnerable road users in the community travelling to school, parks and other neighborhood destinations. Limited cognitive, behavioral and physical abilities make children more susceptible to injuries where infrastructure and interventions are not designed to promote road safety [1]. Pedestrian injury is a major hazard to the health of children in most developed countries. Pedestrian accidents are one of the first causes of injury-related deaths and hospitalizations among children aged 5 to 14 in industrialized countries. Accidents in Italy are the main cause of death and disability in the ages after the first year of life, and most of the fatal ones (about $50 \%$ of the total) are on the road [2].

According to the data from the Italian National Institute of Statistics [2], despite the EU strategic goal of reducing the number of road casualties by $50 \%$ from 2010 to 2020 , in Italy the number of child pedestrian crash fatalities from 0 to 14 years of age has not decreased since 2010 to the present day. The age groups with the highest number of deaths are 0-5 years old and 11-14 years old. Even the number of child pedestrian crash injuries from 0 to 14 years in Italy has remained almost stable since 2010. In this case, the age group with the highest number of injuries is 11-14 years-old. It is also interesting to compare the number of child injuries and fatalities in Italy since 2010 to the present day in every type of road accident (children occupants of motor vehicles, child cyclists and child pedestrians) and the number of child pedestrian injuries and fatalities in the same period of time. While the number of child fatalities in every type of road accident has overall decreased since 2010 to the present date, the number of child pedestrian fatalities is almost stable. As for injuries, both the number of child injuries in every type of road accident and the number of child pedestrian injuries is almost stable.

In Italy, only one third of children walk to school. $33.2 \%$ of them are up to 5 years of age and $41.7 \%$ of them are between 11 and 13 years of age [3]. According to a research by the Policy Studies Institute of London [4], children who go to elementary school on their own are only $7 \%$ in Italy, compared to $41 \%$ in Great Britain and $40 \%$ in Germany.

Although children's travel mode decisions are governed by a complex set of factors, parents are considered as 'gatekeepers' of children's travel mode decisions [5]. In 
order to investigate Italian parents' opinion regarding their children travel to school, a survey was developed. Participants were recruited in person in order to select appropriate participants and in order to provide visual aids and explanations. This methodology of interviewing participants was already used by the authors for previous studies [6]. The main aim of this study was to identify and to analyze the factors that affect Italian parents' propensity to drive their children to school. This is a widespread habit in Italy, so the analysis of these factors can be useful both for the information campaigns aimed at encouraging parents to use alternative means of transport and for the identification of traffic calming measures to be realized on the home-school paths. This would be certainly helpful in order to encourage children to walk to school on their own in conditions of maximum safety. The relationship among the factors that lead parents to choose to drive their children to school rather than walking was investigated. Moreover, the availability of Italian parents to let their children walk to school, if the home-school path was absolutely safe, was analyzed. Here again, the factors affecting this availability were analyzed in order to identify the safety measures to be implemented in order to encourage parents to let their children walk to school. In the end, the two analyses of this study were related to each other in order to understand if the safety measures that positively affect the parents' availability to let their children walk to school, could also discourage the use of cars.

\section{An Overview of the Literature}

A high percentage (about 23\%) of road accidents involving children occur on the home-school paths [7, 8]. The home-school path is indeed the first and most important use of the urban areas for children since they have to travel it daily. Children are exposed to high crash risk near schools [9]. This highlights the need to improve road safety for children, especially for child pedestrians on the home-school paths.

Pedestrian injuries in school-aged children can be reduced by implementing Safe School zone projects [10-12]. Planning school neighborhoods focusing on the needs of child pedestrians and child cyclists by designing accessible schools with low traffic exposure, sidewalks and drop off zones at some distance from the school would increase the potential for walking and cycling to school, and would decrease the need for children to be chauffeured [13]. Moreover, it could decrease the risk of establishing a pattern of car dependence in children that carries over into adolescence and adulthood [14].

In order to guarantee road safety for children going to school, informational strategies and infrastructural interventions should be adopted. Information strategies can be implemented involving both children and their parents. Road education courses, already starting from kindergartens, are an effective policy aimed at educating children on the rules of road behavior $[15,16]$. Parents, on the other hand, through information campaigns can be sensitized towards two main objectives: 1) to keep particularly prudent driving behavior (e.g., reduced speed), 2) to become aware that a traffic accident between a vehicle and a pedestrian always involves serious consequences for children who are victims of accidents. Reference [17] showed that such campaigns are important to raise awareness, but that they should be supplemented with complementary activities in order to be really effective. From a safety point of view, a higher traffic volume could also be associated with an increased risk of pedestrian injury or death [18, 19]. Reference [20] showed that a higher number of vehicles could produce an unpleasant walking environment. Reference [21] demonstrated the effectiveness of traffic calming measures in accident prevention on home-school paths. Among infrastructural interventions, one of the most efficient is the "Safe roads to school program" that uses traffic calming measures to achieve a dual objective: 1) the reduction of speed of vehicles on home-school paths; 2) the reduction of vehicle flows in areas adjacent to schools.

Both information campaigns and infrastructural interventions are therefore aimed at reducing the probability of vehicle-child conflicts that can degenerate into accidents with very serious consequences. Considering that the number of children on home-school paths is high, one possibility to reduce the probability of a child-vehicle accident could be reducing the frequency of motor vehicles. Reference [22] showed that the "Safe Routes to School program" was associated with an increase in walking and biking. They demonstrated in particular that the education program with additional improvements such as sidewalks, crosswalks, covered bike parking was associated with an increase in walking and biking of 5-20 percentage points.

Previous studies also highlighted the importance of including parents' perceptions in analyzing children's travel pattern. Parents determine to a large extent the mode choice of school aged children. In the search for crash risk factors of child pedestrians, parental factors have long been identified as an important aspect for investigation since children are normally in the care of their parents. Many studies have been conducted internationally in the area of parental factors and childhood injuries. Lawrence [23] investigated the factors that affect road risk perception among parents of children aged 4-12 years. Five factors were found to be significantly associated with parental risk perception. They included age of child, sex of parent, employment of parent, living environment, and previous injury experience. Reference [24] focused on 6 to 12 year-old children. Through an extensive survey they investigated the 
controlling factors of parental safety perception on children's travel mode choice. The research showed that traffic infrastructure has a significant impact on parental decision-making concerning children's travel mode choice.

The recent literature also emphasizes the importance of analyzing the home-school paths. Even in the analysis of the risks that children encounter on home-school paths, it is crucial to focus on parents' perceptions. Children are more likely to walk to school if their parents perceive the home-school path as a safe environment. Large and well-maintained sidewalks and safe pedestrian crossings contribute to increase parents' safety perception [25-27].

Although a number of studies have assessed factors affecting travel mode choices for the home-school travel, little is known about Italian parents. This study therefore addresses the lack of knowledge about factors that lead Italian parents to drive their children to school rather than walking. The final aims of this study are: 1 ) to identify the factors affecting Italian parents' propensity to use private cars to accompany their children to school; 2) to analyze the availability of Italian parents to let their children walk to school alone.

\section{Methods}

\subsection{Participants and Questionnaire}

In order to study the factors affecting parents' choice of driving their children to school instead of walking and in order to evaluate their availability to let their children walk to school on their own, an ad hoc questionnaire was developed. The survey comprised a series of questions regarding demographic features, parents' mobility habits, travel mode to school and parents' perception of road risks near the school with a focus on traffic infrastructure. The questionnaire included 21 items and it was divided into the following four sections:

- $\quad$ section 1 (individual demographic): the first section contained questions related to children's demographic characteristics, to parents' demographic characteristics and to the family context;

- section 2 (parents' safety perception of the home-school path): in the second section of the survey, parents were asked questions about the safety perception of the home-school path that they daily travel (driving or walking);
- $\quad$ section 3 (parents' choice of travel mode to school): the third section included questions related to parents' choice of travel mode to school (driving or walking) and questions related to the factors affecting such choice;

- $\quad$ section 4 (parents' availability to let their children walk to school): in the fourth section, parents were asked questions about the road safety measures they considered necessary in order to let their children walk the last road section to school $(200 \mathrm{~m} \div 300 \mathrm{~m})$. Parents were also asked if they would allow their children to walk to school, either on their own or accompanied.

The survey was conducted in front of 9 schools (kindergarten and primary school) in Catania, Italy. Participants were recruited in person, so as to select exclusively parents who were accompanying their children to school. Other people who were accompanying children to school (e.g. grandparents, baby sitters, etc.) were not interviewed. Participants were briefed of the nature and time required to participate in the study prior to commencement. After their consent was obtained, the questionnaire started. It was decided to question directly participants, instead of leaving them alone with the questionnaire, in order to provide visual aids and detailed explanations and clarifications. Each survey lasted approximatively 20 minutes. Participants were assured of anonymity and confidentiality.

The total sample comprised 1576 parents (1002 mothers and 574 fathers). Participants who didn't complete the questionnaire or who gave uncertain answers were excluded. The respondents excluded were about $6 \%$ of the sample. The final sample was composed by 1482 parents (953 mothers and 529 fathers) of children between 3 and 11 years. More than half of children was 6-8 years old, about $20 \%$ of children was 3-5 years old, and $24 \%$ was 9-11 years old. More than half of parents did not have a job. The majority of parents accompanied one child to school, while only $32 \%$ of them accompanied to school more than one child. Private vehicles (car or scooter) were the dominant mode of travel to school: about $81 \%$ of parents drove a car or rode a scooter to accompany their children to school. Very low percentage of parents walked to school with their children. The travel distance from house to school was between $500 \mathrm{~m}$ and $1 \mathrm{~km}$ for most respondents. As for parking availability, more than half of parents couldn't find parking around the school when accompanying children to school. Table 1 compares the sample demographic characteristics. 
Table 1. Features of survey respondents

\begin{tabular}{|c|c|}
\hline \multicolumn{2}{|l|}{ Gender } \\
\hline Mother & $64,30 \%$ \\
\hline Father & $35,69 \%$ \\
\hline \multicolumn{2}{|l|}{ Child's age } \\
\hline $3-5$ & $19,56 \%$ \\
\hline $6-8$ & $56,14 \%$ \\
\hline $9-11$ & $24,30 \%$ \\
\hline \multicolumn{2}{|c|}{ Employment status } \\
\hline Full-time employed & $41,84 \%$ \\
\hline Part-time employed & $4,86 \%$ \\
\hline Not employed, looking for & $53,31 \%$ \\
\hline \multicolumn{2}{|c|}{ Number of children to be accompanied to school } \\
\hline 1 & $68,42 \%$ \\
\hline More than 1 & $31,58 \%$ \\
\hline \multicolumn{2}{|l|}{ Travel mode to school } \\
\hline Private vehicle (car/scooter) & $81,40 \%$ \\
\hline On foot & $18,60 \%$ \\
\hline \multicolumn{2}{|c|}{ Travel distance from house to school } \\
\hline$<500 \mathrm{~m}$ & $23,21 \%$ \\
\hline $500 \mathrm{~m} \div 1 \mathrm{~km}$ & $35,63 \%$ \\
\hline $1 \mathrm{~km} \div 2 \mathrm{~km}$ & $24,97 \%$ \\
\hline$>2 \mathrm{~km}$ & $16,19 \%$ \\
\hline \multicolumn{2}{|c|}{ Parking availability around the school } \\
\hline$<100 \mathrm{~m}$ & $15,79 \%$ \\
\hline $100 \div 300 \mathrm{~m}$ & $6,48 \%$ \\
\hline$>300 \mathrm{~m}$ & $21,19 \%$ \\
\hline No availability & $56,55 \%$ \\
\hline
\end{tabular}

\subsection{Analytical Method}

In order to analyze the survey data a path analysis was carried out. Path analysis is a form of Structural Equation Modelling (SEM) where all the variables are manifest variables (i.e., measureable). SEM is a series of statistical methods that enable the analysis of the relationships between a number of dependent variables (DV) and a set of independent variables (IV). Main aim of SEM is to test the validity of a certain relationship. The variables in a model can be either exogenous (not influenced by any other variable in the model) or endogenous (influenced by other variables in the model). When variables in the model are all manifest, SEM simplifies the analysis to a path analysis, in which mediation, moderation, mediated moderation or moderated mediation can all be tested [28].

Path analysis begins by assuming a specific structure, through which independent and dependent variables are related. This structure is represented by a diagram, the path diagram, and its corresponding equation system. The relations in the diagram are the parameters of the equations to be estimated, called path coefficients and are represented as $p_{i j}$ (the influence of variable $j$ on variable $i$ ). A conventional practice in Path analysis involves the use of standardized variables. Here, path coefficients are analogous to standardized linear regression coefficients. They represent the observed change in the dependent variable, measured in standard deviation units, relative to a one standard deviation change in the independent variable, after controlling all other independent variables with a direct effect on the dependent one. The relationship between two variables is represented by straight arrows or curves with arrows in both extremities. For an endogenous variable, the arrows represent direct causal relationship. Curves with arrows in both extremities represent a simple correlation between exogenous variables. In the model equation system, each dependent variable has a corresponding equation, in which the independent variables are represented by arrows pointing to the direction of the dependent variable. Path analysis consists, then, in estimating the coefficients of these equations (representing the amount of linear association between variables) and in using these estimates to get information on an assumed underlying causal process [29]. Although path analysis has been applied in attitude research in various fields, there are only few attempts within traffic safety [30-32].

\subsection{Model Development}

Path analysis was chosen for this study since it is a technique through which multiple relationships can be tested simultaneously. The final aim was to understand how different factors affect parents' choice of driving their children to school instead of walking. In order to develop the analysis, parents' availability to allow their children to walk to school was taken into account. Therefore, the following two latent variables were considered as endogenous variables: "Driven instead of walking" and "Parents' availability". The exogenous variables were grouped into 4 categories:

- socio-demographic characteristics;

- $\quad$ parents' safety perception;

- $\quad$ reasons why parents choose to drive;

- $\quad$ road safety measures.

Table 2 shows the definition of each variable. The exogenous variables are explained in detail in the following sub-paragraphs. In order to build the path model, some hypotheses related to the relationships between the variables were made. The 6 hypotheses regarding the relationships between the endogenous and the exogenous variables are explained in the following sub-paragraphs. A further hypothesis regards the relationship between the two endogenous variables (hypothesis 7). This hypothesis was made in order to understand how many parents available to let their children walk to school choose the car instead of walking. Therefore, the variable "Parents' availability" is introduced in the model as an endogenous mediator variable. Table 3 summarizes the hypotheses made. Figure 1 shows schematically the hypothesized relationships between the variables. Figure 2 shows the hypothesized path model. 
Table 2. Endogenous variables, mediators and exogenous variables

\begin{tabular}{|c|c|c|}
\hline Variable & Meaning & Values \\
\hline $\begin{array}{l}\text { Driven instead of } \\
\text { walking }\end{array}$ & Parents' choice of driving their children to school instead of walking & $\begin{array}{c}\text { Never } \\
\text { Sometimes } \\
\text { Always } \\
\end{array}$ \\
\hline Number of children & Number of children to be accompanied to school & $\begin{array}{c}1 \\
\text { More than } 1 \\
\end{array}$ \\
\hline Child's age & Age of the youngest child to be accompanied to school & $3 \div 11$ \\
\hline Home-school distance & Home-school distance & $\begin{array}{c}<500 \mathrm{~m} \\
500 \mathrm{~m} \div 1 \mathrm{~km} \\
1 \mathrm{~km} \div 2 \mathrm{~km} \\
>2 \mathrm{~km}\end{array}$ \\
\hline Parking & Parking availability around the school & $\begin{array}{c}<100 \mathrm{~m} \\
100 \div 300 \mathrm{~m} \\
>300 \mathrm{~m} \\
\text { No availability }\end{array}$ \\
\hline Working parent & Working parent & $\begin{array}{c}\text { Not a worker } \\
\text { Part-time worker } \\
\text { Full-time worker }\end{array}$ \\
\hline Car-use habit & Parent's habit of using the car (for any travel) & $\begin{array}{l}\text { No } \\
\text { Yes }\end{array}$ \\
\hline Excessive distance & Excessive distance home-school to walk to school & $\begin{array}{l}\text { No } \\
\text { Yes }\end{array}$ \\
\hline Parent driving to work & Parent drives directly to work after accompanying the child to school & $\begin{array}{l}\text { No } \\
\text { Yes }\end{array}$ \\
\hline Dangerous path & Pedestrian home-school path too dangerous & $\begin{array}{l}\text { No } \\
\text { Yes }\end{array}$ \\
\hline Heavy schoolbag & Too heavy schoolbag to walk to school & $\begin{array}{l}\text { No } \\
\text { Yes }\end{array}$ \\
\hline Child too young & Child too young to walk to school & $\begin{array}{l}\text { No } \\
\text { Yes }\end{array}$ \\
\hline No school bus & Lack of a school bus service & $\begin{array}{l}\text { No } \\
\text { Yes }\end{array}$ \\
\hline Sidewalks & Safe sidewalks (improvement or realization) & $\begin{array}{l}\text { No } \\
\text { Yes }\end{array}$ \\
\hline Speed limits & Reduction of speed limits by means of signs & $\begin{array}{l}\text { No } \\
\text { Yes }\end{array}$ \\
\hline Pedestrian crossings & Safe pedestrian crossing (improvement or realization) & $\begin{array}{l}\text { No } \\
\text { Yes }\end{array}$ \\
\hline Traffic calming & $\begin{array}{l}\text { Realization of traffic calming measures (road bumps, speed cushions, } \\
\text { road width restrictions, chicanes) }\end{array}$ & $\begin{array}{l}\text { No } \\
\text { Yes }\end{array}$ \\
\hline Crossing guards & Presence of crossing guards in front of the school & $\begin{array}{l}\text { No } \\
\text { Yes }\end{array}$ \\
\hline Safety perception & Parents' safety perception of the home-school path & $\begin{array}{c}\text { Low } \\
\text { Medium } \\
\text { High } \\
\end{array}$ \\
\hline Parents' availability & $\begin{array}{l}\text { Parents' availability to let their children walk the last road section to } \\
\text { school ( } 200 \mathrm{~m} \div 300 \mathrm{~m}) \text { if the pedestrian path was really safe }\end{array}$ & $\begin{array}{l}\text { No } \\
\text { Yes, only if accompanied } \\
\text { Yes }\end{array}$ \\
\hline
\end{tabular}

Table 3. Model hypotheses

\begin{tabular}{|l|c|}
\hline & Hypothesis \\
\hline Hypothesis n.1 & "Driven instead of walking” is influenced by “Socio-demographic characteristics” \\
\hline Hypothesis n.2 & "Parents' availability” is influenced by “Socio-demographic characteristics” \\
\hline Hypothesis n.3 & "Parents’ safety perception” of the home-school path influences "Driven instead of walking” \\
\hline Hypothesis n.4 & "Parents' safety perception” of the home-school path influences "Parents' availability” \\
\hline Hypothesis n.5 & "Driven instead of walking” is influenced by “Reasons why parents choose to drive” \\
\hline Hypothesis n.6 & "Parents' availability” is influenced by "Road safety measures” \\
\hline Hypothesis n.7 & "Parents' availability” is a mediator variable for "Driven instead of walking” \\
\hline
\end{tabular}




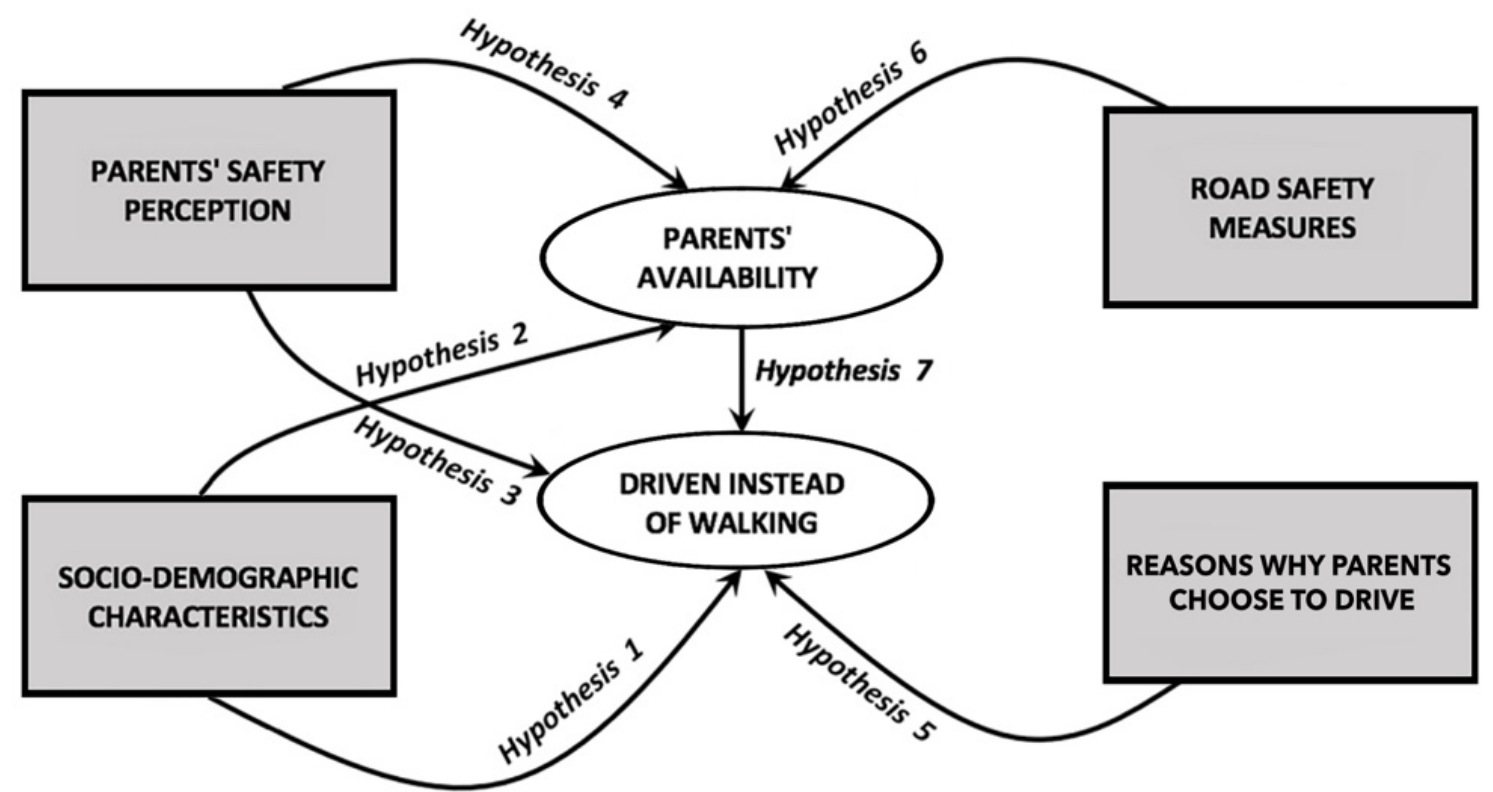

Figure 1. Hypothesis scheme

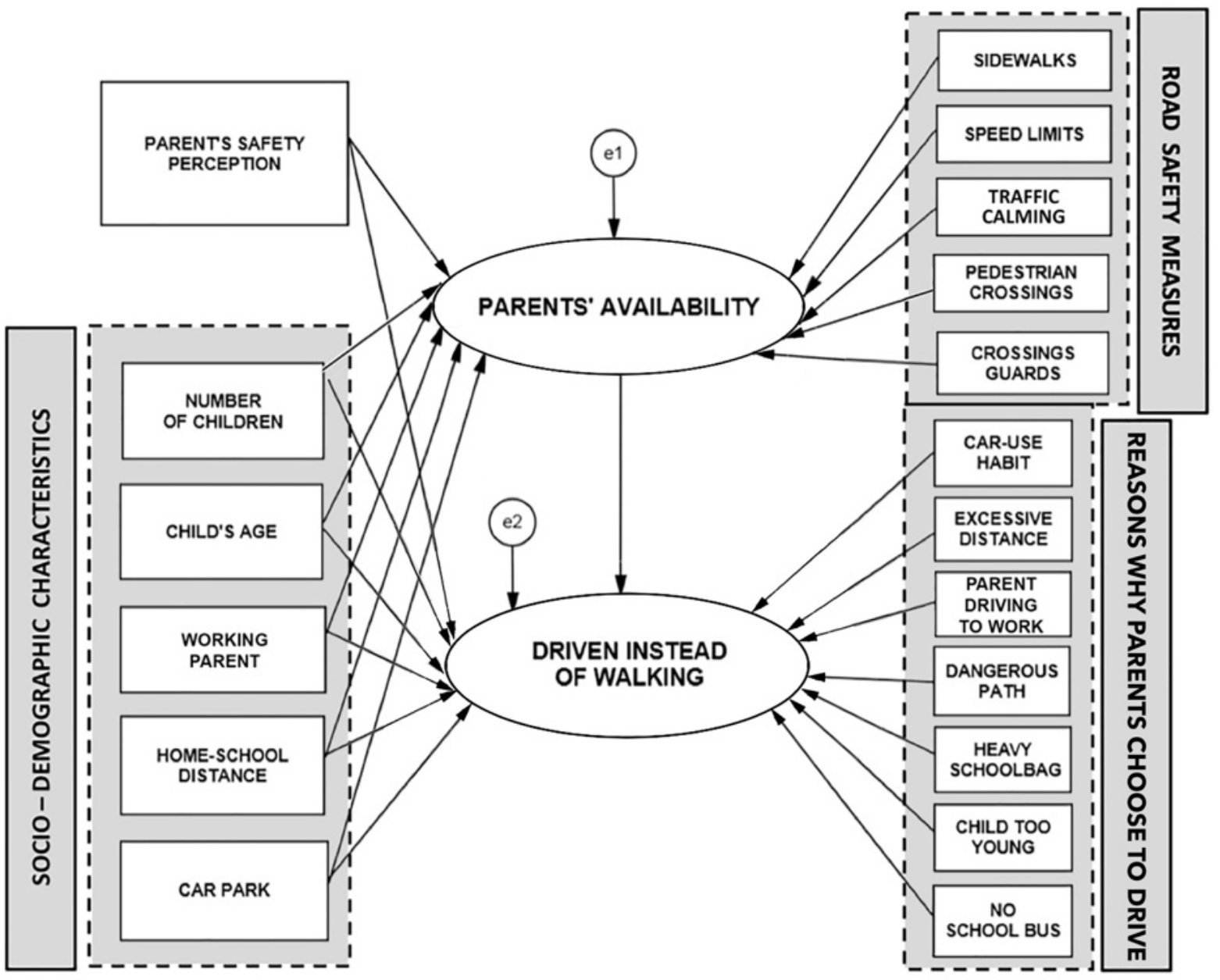

Figure 2. Hypothesized path model 


\subsubsection{Socio-demographic Characteristics}

Previous studies showed that children's age strongly contributes to parents' willingness to walk to school [33-35]. Reference [36] explored the association between walking to school and physical (distance from home to school and number of cars in the household) and social (working situation of parents, number of siblings) environmental characteristics in the home. Distance between home and school may influence how parents evaluate their children's ability to walk on their own, which in turn affects the decision to take (or not to take) the car [37]. Reference [38] indicated that the number of parents available to allow their children to walk to school decreased as a function of the time spent walking.

Based on the results of these studies, the "Socio-demographic characteristics" considered in this study are: "Child's age", "Number of children", "Home-school distance", "Working parent", "Parking" (Table 2). The variable "Parking" was introduced in order to take into account that the choice of driving instead of walking is often encouraged by the awareness of finding a regular or irregular parking space near the school. It was hypothesized that all "Socio-demographic characteristics" influence both the variable "Driven instead of walking" (hypothesis 1) and the variable "Parents' availability" (hypothesis 2).

\subsubsection{Parents' Safety Perception}

Children are more likely to walk to school if their parents have positive opinions about the safety of the home-school path [25, 27]. Parental perception of social and traffic danger is often a factor that limits the possibility of walking for children. Hillman [39] believes that, more than social fear, parental concern is the risk of road injury to their children when they are alone. Therefore, in this study it was hypothesized that the exogenous variable "Parents' safety perception" influences both the variable "Driven instead of walking" (hypothesis 3) and the variable "Parents' availability" (hypothesis 4).

\subsubsection{Reasons Why Parents Choose to Drive}

Reference [40] showed that reasons why parents choose to drive their children to school can be described as social convenience (related to parents' convenience of using the car) and safety (related to parents' concerns about their children encountering difficulties on their way to school). The results further showed that distance does not strongly affect the decision to drive since lots of parents choose to drive even for a short distance. Reference [41] introduced the weight of schoolbags as a relatively new factor among the reasons why parents choose to drive.

Based on the results of these studies and considering the reasons parents stated during the survey we developed, the "Reasons why parents choose to drive" considered in this study are: "Car use habit", "Excessive distance", "Parent driving to work", "Dangerous path", "Heavy schoolbag", "Child too young" and "No school bus" (Table 2). It was hypothesized that all these variables influence only the variable "Driven instead of walking" (hypothesis 5).

\subsubsection{Road Safety Measures}

Traffic safety has a significant impact on parental decision-making concerning children's travel mode choice [24, 42]. Reference [21] showed that traffic calming measures are strongly, significantly, and positively correlated with the percentage of students walking or cycling to school. Previous parent surveys revealed that parents are most likely to feel concern about streets that lack sidewalks or have sidewalks with obstructions [43], that the speed of cars is their highest concern [10] and that traffic controls do not modify their concern [43]. Walking to school is more frequent among children attending schools in neighborhoods of low traffic volume [44]. Reference [45] showed that the number of crossings, the width of the road and the presence of crosswalks are significantly and positively associated with perceived crash risk among school-aged children.

The "Road safety measures" considered in this study result directly from what parents declared during the survey. The road safety measures that parents declared would like to be realized or improved on the home-school path in order to let their children walk to school were therefore considered as variables for this study. These variables are: "Sidewalk", "Speed limits", "Traffic reduction", "Pedestrian crossings", and "Crossing guards" (Table 2). It was hypothesized that the variables of this category affect only the variable "Parents' availability" (hypothesis 6).

\section{Results and Discussion}

Path analysis enables to estimate all the model parameters at the same time. This is a very efficient method of estimation and provides reliable estimates. Path estimates can be interpreted as regression coefficients and moderation effects. In this study, they were estimated using AMOS 24.0.

Table 4 shows the mean scores of the path analysis: unstandardized coefficients estimates with relative standard errors, standardized coefficients and p-value. Unstandardized coefficients estimates retain scaling information of variables involved and can only be interpreted with reference to the scales of the variables. Standardized coefficients estimates are transformations of unstandardized estimates that remove scaling information and can be used for informal comparisons of parameters throughout the model. Standardized estimates correspond to effect size estimates. 
Table 4. Modelling results

\begin{tabular}{|c|c|c|c|c|c|}
\hline & Variable & Estimate & Standard Errors & Standardized coefficients & p-value* \\
\hline \multirow[t]{14}{*}{ Driven instead of walking } & Car-use habit & 0.331 & 0.031 & 0.199 & $<0,001$ \\
\hline & Excessive distance & 0.067 & 0.031 & 0.041 & 0.029 \\
\hline & Parent driving to work & 0.142 & 0.030 & 0.090 & $<0,001$ \\
\hline & Dangerous path & 0.016 & 0.039 & 0.008 & 0.688 \\
\hline & Heavy schoolbag & 0.002 & 0.034 & 0.001 & 0.944 \\
\hline & Child too young & 0.154 & 0.044 & 0.066 & $<0,001$ \\
\hline & No school bus & -0.001 & 0.033 & -0.001 & 0.972 \\
\hline & Number of children & 0.139 & 0.026 & 0.123 & $<0,001$ \\
\hline & Child's Age & 0.027 & 0.007 & 0.075 & $<0,001$ \\
\hline & Working parent & 0.124 & 0.014 & 0.169 & $<0,001$ \\
\hline & Home-school distance & 0.343 & 0.014 & 0.485 & $<0,001$ \\
\hline & Parking & 0.232 & 0.012 & 0.361 & $<0,001$ \\
\hline & Safety perception & -0.018 & 0.018 & -0.019 & 0.321 \\
\hline & Parents’ availability & -0.059 & 0.022 & -0.055 & 0.006 \\
\hline \multirow[t]{11}{*}{ Parents' availability } & Number of children & 0.131 & 0.030 & 0.105 & $<0,001$ \\
\hline & Child’s Age & 0.086 & 0.008 & 0.254 & $<0,001$ \\
\hline & Working Parent & 0.077 & 0.016 & 0.112 & $<0,001$ \\
\hline & Home-school distance & -0.107 & 0.016 & -0.168 & $<0,001$ \\
\hline & Parking & 0.016 & 0.014 & 0.027 & 0.260 \\
\hline & Safety perception & 0.027 & 0.021 & 0.030 & 0.210 \\
\hline & Sidewalks & 0.041 & 0.032 & 0.030 & 0.208 \\
\hline & Speed limits & -0.039 & 0.032 & -0.029 & 0.223 \\
\hline & Pedestrian crossings & 0.076 & 0.032 & 0.067 & 0.017 \\
\hline & Traffic calming & 0.202 & 0.032 & 0.141 & $<0,001$ \\
\hline & Crossing guards & 0.064 & 0.033 & 0.047 & 0.049 \\
\hline
\end{tabular}

The results of the path analysis are shown as a pyramid diagram [46]. The pyramid diagram has a hierarchical structure and it is subdivided into a number of sections equal to the variables that have statistically significant effects on the endogenous variables (p-value $<0.05$ ). At the top of the pyramid there are the exogenous variables characterized by standardized coefficients closest to the perfect relationship, positive or negative, with the endogenous variables. Each section can be identified by the sign "+" or "-" and relates to the exogenous variable that has a significant association with the endogenous variable, positively or negatively.

The variables related to each section are sorted in descending order on the basis of the absolute value of the standardized coefficients; such sorting gives rise to the ordered sequence of the signs attributed to the single sections constituting the pyramid structure. Thanks to the pyramid diagram, it is possible to visualize clearly the existing relationships between the endogenous and the exogenous variables.

In Figure 3 the values on the arrows are the standardized coefficients estimates between the variables. These values represent the standardized relationships between the variables and can range between -1.0 (perfect negative relationship) and 1.0 (perfect positive relationship), with 0.0 meaning no relationship. Thus, if variable $\mathrm{X}$ has a 0.50 effect on variable $\mathrm{Y}$, it means that for every standard deviation increasing $\mathrm{X}, \mathrm{Y}$ will increase by 0.50 standard deviations. Indirect effects are interpreted by multiplying coefficients along a path. 


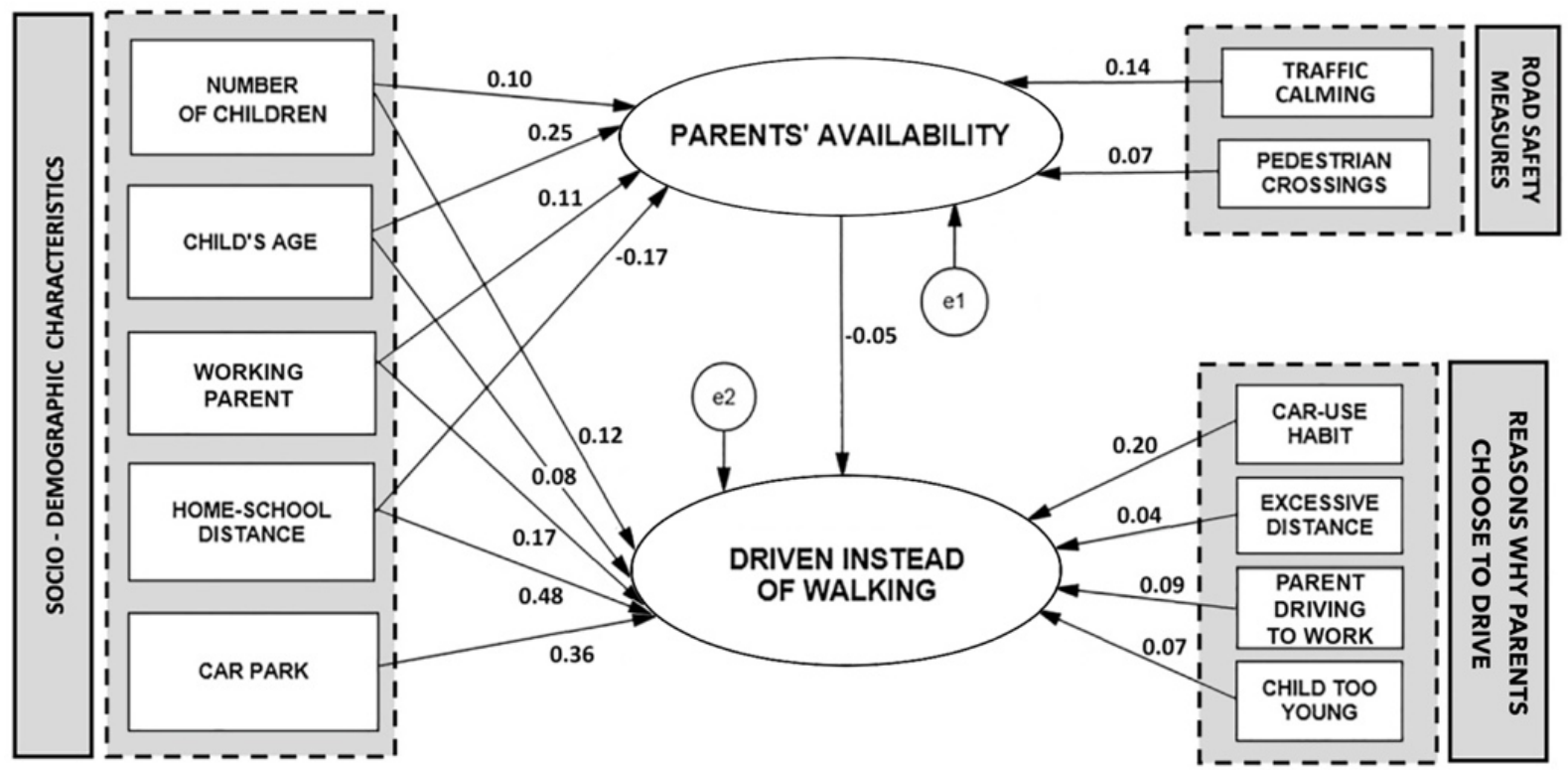

Figure 3. Hypothesized Final Path Diagram

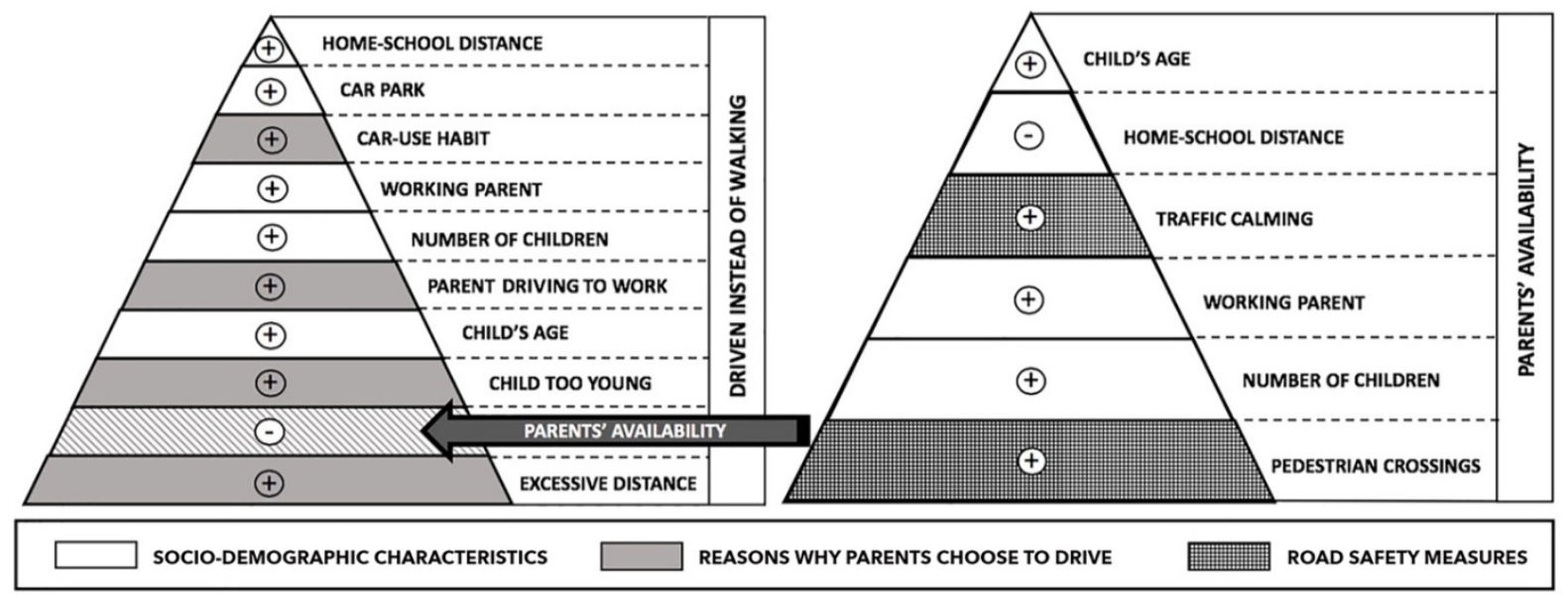

Figure 4. Pyramid Diagram

\subsection{Parents' Availability}

The analysis of Table 4 leads to the conclusion that four out of five variables belonging to the category of "Socio-demographic characteristics" are statistically significant ( $\mathrm{p}$-value $<0,05$ ) for the mediator variable "Parents' availability". Hypothesis 2 is therefore partially verified. The variables mostly influencing "Parents' availability" are "Child's age" and "Home-school distance". They are indeed at the top of the pyramid diagram related to "Parents' availability” (Figure 4).

The maximum positive correlation of the variable "Child's age" shows that the older children are, the more parents are predisposed to let their children walk to school alone, even if for the last part of the travel (a few hundred meters). The negative correlation of the variable "Home-school distance" shows that the excessive home-school distance encourages parents to drive their children to school. The other two variables belonging to the category of "Socio-demographic characteristics", i.e. "Working parent" and "Number of children", have a positive correlation with "Parents' availability". It is not surprising that the variable "Working parent" has the same sign and it is in a similar position both in the pyramid diagram related to "Parents' availability" and in the pyramid diagram related to "Driven instead of walking". In the pyramid diagram related to "Driven instead of walking" the positive correlation of the variable "Working parent" can be explained considering that the condition of working parent encourages the use of the car. On the other hand, in the pyramid diagram related to "Parents' availability" the positive correlation of the variable "Working parent" can be explained considering that the social level of parents who have a stable job affects positively their predisposition to let their children walk the last part of the home-school path.

Hypothesis 4 (i.e. "Parents' safety perception" of the home-school path influences "Parents' availability") is not 
confirmed. The variable "Parents' safety perception" is indeed statistically not significant (p-value of 0,210 ) and it is not therefore represented in the pyramid diagram.

As for the variables belonging to the category "Road safety measures", only "Traffic calming” and "Pedestrian crossings" are statistically significant. Hypothesis 5 is thus partially verified. The variable of this category most influencing "Parents' availability" is "Traffic calming", which is in the upper section of the central area of the pyramid diagram. Aggressive driving behaviors towards pedestrians and parking maneuvers near the school are indeed factors that lead parents to consider traffic reduction as a priority. The variable "Pedestrian crossings" is at the base of the pyramid diagram, even though has a positive correlation with "Parents' availability".

\subsection{Driven Instead of Walking}

From Table 4 it can be seen that only four out of seven variables of the category "Reasons why parents choose to drive" are statistically significant (p-value $<0,05$ ) for the variable "Driven instead of walking". Hypothesis 5 is therefore partially verified. The pyramid diagram related to the variable "Driven instead of walking" (Figure 4) shows that the variable mostly influencing "Driven instead of walking" is "Car-use habit". It is indeed in the upper section of the pyramid diagram related to "Driven instead of walking" (Figure 4). This is a confirmation of the established Italians' habit of using a private vehicle, excluding a priori other means of transport. The variable "Parent driving to work" also has a quite important positive correlation with the endogenous variable "Driven instead of walking" (in fact it is in the central part of the pyramid diagram). Family organization plays indeed an important role in choosing a private vehicle because the working parent plans the home-school-work itinerary compatibly with their children's school and their work starting times. The variables "Child too young" and "Excessive distance" are at the base of the pyramid and they therefore contribute less in encouraging parents to use a private vehicle.

All the variables belonging to the category "Socio-demographic characteristics" are correlated positively to "Driven instead of walking". Hypothesis 1 is therefore verified. Parents' choice of a means of transport is mostly influenced by the two variables "Home-school distance" and "Parking". They are indeed at the top of the pyramid diagram related to "Driven instead of walking". This means that excessive length of home-school paths discourages parents from walking. Moreover, parents' awareness of finding parking spaces near the school encourages the use of the car. The variables "Working parent" and "Number of children" are at the center of the pyramid and also have a positive correlation with "Driven instead of walking". The variable "Child's age" is close to the base of the pyramid diagram, even though it has a positive correlation with "Driven instead of walking”, and therefore it does not seem to have a strong influence on parents' choice of driving.

It is interesting to note that both the variables associated to children's age (i.e. "Child too young" and "Child's age") are at the bottom of the pyramid diagram related to the endogenous variable "Driven instead of walking". However, it is believed that this is not representative of the low influence of these variables on the endogenous variable. Rather, the context of analysis limited exclusively to young children (from 3 to 10 years old) probably overshadows the influence of children's age on parents' choices. Respondents are indeed parents of children attending kindergarten and/or primary school. That is precisely why the importance of children's age does not arising clearly neither from the questions related to "Reasons why parents choose to drive", nor from the analysis of the variables related to "Socio-demographic characteristics".

It is also interesting to note that the variable "Home-school distance" is at the top of the pyramid diagram while the variable "Excessive distance" is at the base. This apparent contradiction can be explained considering that some parents live near the school, others live far away. The variable "Home-school distance" is objective and independent from the respondents' statements and it therefore attests the strong influence of the home-school distance on the choice of driving. The variable "Excessive distance" is the result of parents deliberately saying that the excessive distance home-school is one of the reasons why they choose to drive. This is why it has a weak influence on the choice of the means of transport.

Hypothesis 3 (i.e. "Parents' safety perception" of the home-school path influences "Driven instead of walking") was not verified. The variable "Parents' safety perception" is indeed statistically not significant (p-value of 0,321 ) and it is therefore not represented in the pyramid diagram. Parents' preference for the car is indeed not affected by their perception of the home-school path as totally unsafe. It is interesting that both the variable "Dangerous path" (belonging to the category "Reasons why parents choose to drive") and the variable "Parents' safety perception" are statistically not significant although they were deduced from different sections of the questionnaire. The dangerousness of the home-school path does not affect the choice of the means of transport.

Finally, the results show that there is a negative correlation between the mediator variable "Parents' availability" and the endogenous variable "Driven instead of walking" (hypothesis 7); this means that parents who are more available to let their children walk to school are mentally predisposed to drive less. The low absolute value of the standardized coefficient associated to the correlation between "Parents' availability" and "Driven instead of walking” suggests that other variables affect more parents' preference for the car. However, the combined analysis of 
the path diagram and of the pyramid diagram shows that the realization of measures favoring "Parents' availability" is essential in order to mitigate the preference for the private vehicle, still deeply rooted in Italy. It is believed that by encouraging "Parents' availability" in the near future it could be obtained a new pyramid diagram related to the endogenous variable "Driven instead of walking" where "Car-use habit" gets closer to the base and, vice versa, "Parents' availability" gets closer to the top of the pyramid.

\section{Conclusions}

This paper final aim was to investigate the reasons that lead Italian parents to drive their children to school rather than walking. Furthermore, parents' availability to let their children walk to school alone has been tested. The results show that the habit of driving children to school is still very common in Italy. Main reasons why parents drive their children to school are the lack of safe home-school paths and the availability of regular or irregular parking spaces near the school. These results can be useful for those involved in transport planning and safety in order to implement effective actions aimed at encouraging the use of one or several human-powered modes of transportation such as walking or cycling. Several recent studies demonstrated the effectiveness of information and sensitization strategies, such as "Safe Routes to School" (SRTS) programs in the US. References [47, 48] evaluated the impact of "Safe Routes to School" using large samples of schools and SRTS projects, and reported a significant increase in the rate of students walking or cycling to school among those that participated in SRTS programs.

In Italy, little has been done in order to discourage the use of private vehicles and encourage walking and cycling to school. The results of this study could be very helpful for developing guidelines on implementation of policies to improve the safety of home-school paths. This research confirms the importance of information and sensitization strategies, which should be implemented involving both children and their parents. The results furthermore suggest that infrastructure-centered interventions, such as traffic calming measures and safer pedestrian crossings, can increase parents' safety perception of the home-school paths and thus raise the probability that children walk to school. It is in everyone's interest that traffic environments are suitable for children from both safety and functional points of view. If an appropriate protection of children were guaranteed, parents would be encouraged to let them walk to school, which would turn into decreasing risk of car dependence for future adults. Moreover, there would be the collateral benefit of getting children used to the traffic environments from an early age, which would lead them to develop a great civic sense and to evolve into appropriate road users when adults.

\section{Acknowledgements}

This work has been partially financed by the University of Catania within the project "Piano della Ricerca Dipartimentale 2016-2018" of the Department of Civil Engineering and Architecture.

\section{REFERENCES}

[1] Safe Kids USA, Raising Kids One Stage at a Time: A Study of Child Development and Unintentional Injury, Washington DC, 2009.

[2] ISTAT. Incidenti stradali. Anno 2017. Online available from Online available from https://www.istat.it/it/files//20 18/07/Incidenti-stradali_2017.pdf, 2018

[3] ISTAT. Vanno a scuola da soli. Anno 2014. Online available from https://www.istat.it/it/archivio/203475 , 2015

[4] B. Shaw, M. Bicket, B. Elliott, B. Fagan-Watson, E. Mocca, M. Hillman. Children's Independent Mobility: an international comparison and recommendations for action. Policy Studies Institute, 2015.

[5] S. K. Mah, L. Nettlefold, H. M. Macdonald, M. Winters, D. Race, C. Voss, H. A. McKay. Does parental support influence children's active school travel? Preventive Medicine Reports 6, 346-351, 2017.

[6] N. Distefano, S. Leonardi, G. Pulvirenti. Multiple Correspondence Analysis (MCA) for the evaluation of risk perception of roundabouts for young people. European Transport / Trasporti Europei. IN PRESS.

[7] J. Warsh, L. Rothman, M. Slater, C. Steverango, A. Howard. Are school zones effective? An examination of motor vehicle versus child pedestrian crashes near schools. Injury Prevention, 15(4), 226-239, 2009.

[8] A. Macpherson, I. Roberts, I. B. Pless. Children's exposure to traffic and pedestrian injuries. American Journal of Public Health 88(12), 1840-1843, 1998.

[9] M. Abdel-Aty, S. S. Chundi, C. Lee. Geo-spatial and log-linear analysis of pedestrian and bicyclist crashes involving school-aged children. Journal of Safety Research 38(5), 571-579, 2007.

[10] P. Gautam, K. Rosenthal. Model school zone pilot project demonstrates results in improving pedestrian safety. Injury Prevention 22 (Suppl 2), A323, 2016.

[11] C. Dimaggio, G. Li. Effectiveness of Safe Routes to School Program in Preventing School-Aged Pedestrian Injury. Pediatrics 131(2), 290-296, 2013.

[12] M. G. Boarnet, K. Day, C. Anderson, T. McMillan, M. Alfonzo. California's Safe Routes to School Program: Impacts on Walking, Bicycling, and Pedestrian Safety. Journal of the American Planning Association 71(3), 301317, 2005.

[13] R. Ewing, W. Schroeer, W. Green. School location and student travel-Analysis of factors affecting mode choice. 
Transportation Research Record 1895, 55-63, 2004.

[14] B. Giles-Corti, S. F. Kelty, S. R. Zubrick, K. P. Villaneuva. Encouraging walking for transport and physical activity in children and adolescents: How important is the built environment? Sports Medicine 39, 995-1009, 2009, 2009.

[15] G. Hotz, S. Cohn, A. Castelblanco, S. Colston, M. Thomas, A. Weiss, J. Nelson, R. Duncan. WalkSafe: a school-based pedestrian safety intervention program. Traffic Injury Prevention 5(4), 382-389, 2004.

[16] S. Treviño-Siller, L. E. Pacheco-Magaña, P. Bonilla-Fernández, C. Rueda-Neria, C. Arenas-Monreal. An educational intervention in road safety among children and teenagers in Mexico, Traffic Injury Prevention, 18(2): 164-170, 2016.

[17] R. Zampetti, G. Messina, C. Quercioli, F. Vencia, L. Genco, L. Di Bartolomeo, N. Nante. Non-fatal Road Traffic Injuries: Can Road Safety Campaigns Prevent Hazardous Behavior? An Italian Experience. Traffic Injury Prevention 14 (3), 261-266, 2013.

[18] C. Y. Yu, X. M. Zhu. Planning for Safe Schools: Impacts of School Siting and Surrounding Environments on Traffic Safety. Journal pf Planning education and Research 36(4), 476-486, 2016.

[19] S. Canale, N. Distefano, S. Leonardi. Comparative analysis of pedestrian accidents risk at unsignalized intersections. The Baltic Journal of Road and Bridge Engineering, vol.10, n.4, 2015.

[20] K. Larsen, R. N. Buliung, G. E. J. Faulkner. Safety and School Travel: How Does the Environment Along the Route Relate to Safety and Mode Choice? Transportation Research Record 2327(1), 9-18, 2013.

[21] L. M. Nicholson, L. Turner, S. J. Slater, H. Abuzayd, J. F. Chriqui, F. Chaloupka. Developing a Measure of Traffic Calming Associated with Elementary School Students' Active Transport. Transportation Research Part D: Transport and Environment 33, 17-25, 2014.

[22] N. C. McDonald, Y. Yang, S. M. Abbott, A. N. Bullock. Impact of the Safe Routes to School program on walking and biking: Eugene, Oregon study. Transport Policy 29, 243-248, 2013.

[23] T. L. Lawrence. Parental risk perceptions of childhood pedestrian road safety, Journal of Safety Research, 32: 465478, 2001.

[24] K. Nevelsteen, T. Steenberghen, A. Van Rompaey, L. Uyttersprot. Controlling factors of the parental safety perception on children's travel mode choice. Accident Analysis and Prevention 45, 39-49, 2012.

[25] A. O. Oluyomi, C. Lee, E. Nehme, D. Dowdy, M. G. Ory, D. M. Hoelscher. Parental safety concerns and active school commute: correlates across multiple domains in the home-to-school journey. International Journal of Behavioral Nutrition and Physical Activity 11, 32, 2014.

[26] A. Guliani, R. Mitra, R. N. Buliung, K. Larsen, G. E. J. Faulkner. Gender-based differences in school travel mode choice behaviour: Examining the relationship between the neighbourhood environment and perceived traffic safety. Journal of Transport \& Health 2, 502-511, 2015.
[27] A. Carver, J. Salmon, K. Campbell, L. Baur, S. Garnett, D. Crawford. How do perceptions of local neighborhood relate to adolescents' walking and cycling? American Journal of Health Promotion 20,139-147, 2005.

[28] A. J. Fairchild, D. P. Mac Kinnon. A General Model for Testing Mediation and Moderation Effects. Prevention Science 10(2), 87-99, 2009.

[29] C. Glisson, H. M. Mok. Incorporating nominal variables in path analysis: A cross-cultural example with human service organizations. The Journal of Applied Behavioral Sciences, 19(1), 95-102, 1983.

[30] V. M. Puchades, F. Fassina, F. Fraboni, M. De Angelis, G. Prati, D. de Waard, L. Pietrantoni. The role of perceived competence and risk perception in cycling near misses. Safety Science 105, 167-177, 2018.

[31] S. A. Gargoum, K. El-Basyouny. Exploring the association between speed and safety: A path analysis approach. Accident Analysis and Prevention 93, 32-40, 2016.

[32] C. Cherry, B. Donlon, X. Y. Yan, S. E. Moore, J. Xiong. Illegal mid-block pedestrian crossings in China: gap acceptance, conflict and crossing path analysis. International Journal of Injury Control and Safety Promotion 19(4), 320-330, 2012.

[33] J. G. Su, M. Jerrett, R. McConnell, K. Berhane, G. Dunton, K. Shankardass, K. Reynolds, R. Chang, J. Wolch. Factors Influencing Whether Children Walk to School. Health Place, 22: 153-161, 2013.

[34] B. A. Morrongiello, B. K. Barton. Child pedestrian safety: parental supervision, modeling behaviors, and beliefs about child pedestrian competence. Accident Analysis and Prevention 41, 1040-1046, 2009.

[35] L. T. Lam. Parental risk perceptions of childhood pedestrian road safety. Journal of Safety Research 32, 465- 478, 2001.

[36] M. J. Aarts, J. J. Mathijssen, J. A. van Oers, A. J. Schuit Associations between Environmental Characteristics and Active Commuting to School among Children: a Cross-sectional Study. International Society of Behavioral Medicine 20(4), 538-555, 2012.

[37] O. Stewart, A. Vernez-Moudon, C. Claybrooke, Common ground: eight factors that influence walking and biking to school. Transport Policy 24, 240-248, 2012.

[38] A. Simons, K. Koekemoer, A. van Niekerk, R. Govender. Parental supervision and discomfort with children walking to school in low-income communities in Cape Town, South Africa. Traffic Injury Prevention. https://doi.org/10.1080/15389588.2017.1420904, 2018.

[39] M. Hillman. Curbing children's social and emotional development: An unrecognised outcome of parental fears. Journal of Contemporary Health 8, 38-42, 1999/2000.

[40] J. Westman, M. Friman, M., L. E. Olsson. What Drives Them to Drive? - Reasons Why Parents Drive to School to Take Their Children to School. Frontiers in Psychology, 8: 1970. Doi:10.3389/fpsyg.2017.01970, L.E., 2017.

[41] H. Zhou, J. Yang, P. Hsu, S. Chen. Factors Affecting Students' Walking/Biking Rates: Initial Findings from a Safe Route to School Survey in Florida. Journal of 
Transportation Safety \& Security 2, 14-27, 2010.

[42] M. S. Cloutier, J. Bergeron, P. Apparicio. Predictors of parental risk perceptions: the case of child pedestrian injuries in school context. Risk Analysis 31(2), 312-323, 2011.

[43] C. Evers, S. Boles, D. Johnson-Shelton, M. Schlossberg, D. Richey. Parent safety perceptions of child walking routes. Journal of Transport \& Health 1(2), 108-115, 2014.

[44] B. Giles-Corti, G. Wood, T. Pikora, V. Learnihan, M. Bulsara, K. Van Niel, A. Timperio, G. McCormack, K. Villanueva. School site and the potential to walk to school: The impact of street connectivity and traffic exposure in school neighborhoods. Health \& Place17, 545-550, 2011.

[45] G. Lee, Y. Park, J. Kim, G. Cho. Association between intersection characteristics and perceived crash risk among school-aged children. Accident Analysis and Prevention 97,111-121, 2016.

[46] N. Distefano, S. Leonardi, G. Pulvirenti. Factors with the greatest influence on drivers' judgment of roundabouts safety. An analysis based on web survey in Italy. IATSS Research. Vol. 42, Issue 4, Pages 265-273. DOI: 10.1016/j.iatssr.2018.04.002, 2018

[47] N. C. McDonald, Y. Yang, S. M. Abbott, A. N. Bullock. Impact of the Safe Routes to School Program on walking and cycling. Journal of the American Planning Association 80(2), 153-167, 2014.

[48] O. Stewart, A. V. Moudon, C. Claybrooke. Multistate evaluation of Safe Routes to School Programs. American journal of health promotion 28 (3), 89 -96, 2014. 